e-Neuroforum 2015 - 6:113

DOI 10.1007/s13295-015-0018-7

Published online: 17 November 2015

(c) Springer-Verlag Berlin Heidelberg 2015

CrossMark
Niels Birbaumer ${ }^{1,2} \cdot$ Ujwal Chaudhary $^{1}$

${ }^{1}$ Institute for Medical Psychology and Behavioral Neurobiology, University of Tübingen, Tübingen, Germany ${ }^{2}$ IRCCS, Ospedale San Camillo, Venice, Italy

\section{Erratum to: Learning from brain control: clinical application of brain-computer interfaces}

\section{Erratum to:}

e-Neuroforum (2015)

DOI 10.1007/s13295-015-0015-x

The co-author Ujwal Chaudhary was inadvertently omitted from the manuscript supplied for publication.

\section{Corresponding address}

\section{N. Birbaumer}

Institute for Medical Psychology and Behavioral Neurobiology,

University of Tübingen

Otfried-Müller-Straße 25, 72076 Tübingen

birbaumer@uni-tuebingen.de 